\title{
Las políticas culturales vistas desde la ciudadanía. Una exploración de experiencias de participación en las Usinas culturales (2008-2015)
}

\author{
Cultural policies from citizenship's perspective. An exploration of \\ participation experiences in Usinas culturales (2008-2015)
}

\section{Políticas culturais na perspectiva dos cidadãos. Uma exploração de experiências de participação nas Usinas culturales (2008-2015)}

\author{
Deborah Duarte Acquistapace ${ }^{1}$
}

\begin{abstract}
Resumen
El objetivo de este artículo es describir y analizar experiencias de participación ciudadana en un programa de política cultural de Estado, las Usina culturales. Las Usinas fueron concebidas desde la perspectiva de los derechos culturales, particularmente la democratización, no solo del acceso sino también de la producción de bienes culturales. Se trata de centros de producción audiovisual y musical ubicados en territorios donde existen grandes poblaciones en situación de vulnerabilidad o notorios déficits de infraestructura cultural (barrios de contexto crítico, centros penitenciarios, hospitales siquiátricos públicos y distintas ciudades del interior del país). No tienen como objetivo fundamental procurar formación artística, sino más bien proporcionar herramientas para que las personas concreten un producto (por ejemplo, en el caso de las Usinas de música, estudio de grabación, técnico en edición y producción de sonido y sala de instrumentos). Por tanto, trataremos con personas con una historia vinculada a determinada práctica artística que por distintas razones recurren a la Usina. Nuestro objetivo será explorar cómo influye, si es que lo hace, su pasaje por la Usina en el desarrollo posterior de sus prácticas artísticas y de sus historias de vida. El trabajo de campo se centró en cuatro experiencias de participación en tres Usinas ubicadas en barrios de contexto crítico en Montevideo. Del análisis surge que la variedad de sentidos atribuidos a las experiencias en las Usinas adquieren significado en relación a las trayectorias sociales y a las historias singulares de las prácticas artísticas respectivas. En algunos casos, las Usinas sirvieron para complementar y enriquecer un trabajo artístico que ya se venía desarrollando, en otros, por el contrario, no resultaron la herramienta adecuada para visibilizar la manifestación en cuestión. Asimismo, el pasaje por las Usinas se relaciona con un proceso más amplio de autoanálisis y con la vivencia de un reconocimiento situado.
\end{abstract}

Palabras claves: cultura, derechos culturales, participación, políticas culturales

Abstract

The objective of this article is to describe and analyze experiences of citizen participation in a State cultural policy program, the Usinas culturales. The Usinas were conceived from the perspective of cultural rights, particularly the democratization not only of access but also of the production of cultural goods. These are

1 Doctoranda en Ciencias Sociales, Universidad de Buenos Aires; Maestría en Estudios Latinoamericanos, Universidad de Barcelona. Docente/investigadora en el Centro de Estudios Interdisciplinarios Latinoamericanos (CEIL), Facultad de Humanidades y Ciencias de la Educación, Universidad de la República. debdua@gmail.com 
audiovisual and musical production centers located in territories where large populations are vulnerable or notorious cultural infrastructure deficits (critical context neighborhoods, prisons, public psychiatric hospitals and different cities in the interior of the country). They are not primarily aimed at seeking artistic training, but rather providing tools for people to concrete a product (e.g. in the case of music plants, recording studio, sound editing and production technician and instrument room). Therefore, we will deal with people with a history linked to a certain artistic practice who for different reasons turn to the Usina. Our objective will be to explore how, if at all, their passage through the Usina influences the subsequent development of their artistic practices and their life stories. The fieldwork focused on four experiences of participation in three Usinas located in critically context neighborhoods in Montevideo. From the analysis emerges that the variety of senses attributed to the experiences in the Usinas take meaning in relation to the social trajectories and the unique stories of the respective artistic practices. In some cases, the Usinas served to complement and enrich an artistic work that had already been developed, in others, on the contrary, they were not the right tool to make the manifestation in question visible. In addition, the passage through the Usinas relates to a broader process of self-analysis and the experience of a located recognition.

Keywords: cultural policies, participation, culture, cultural rights

\section{Resumo}

O objetivo deste artigo é descrever e analisar experiências de participação cidadã em um programa de política cultural do Estado, as Usinas Culturais. As Usinas foram concebidas na perspectiva dos direitos culturais, particularmente a democratização não só do acesso, mas também da produção de bens culturais. São centros de produção audiovisual e musical localizados em territórios onde grandes populações são vulneráveis ou notórias déficits de infraestrutura cultural (bairros de contexto crítico, prisões, hospitais psiquiátricos públicos e diferentes cidades do interior do país). Eles não visam principalmente buscar formação artística, mas sim fornecer ferramentas para as pessoas concretizarem um produto (por exemplo, no caso de plantas musicais, estúdio de gravação, edição de som e técnico de produção e sala de instrumentos). Portanto, trataremos de pessoas com uma história ligada a uma determinada prática artística que, por diferentes razões, recorrem à Usina. Nosso objetivo será explorar como, se de alguma forma, a passagem pela Usina influencia o desenvolvimento posterior de suas práticas artísticas e de suas histórias de vida. O trabalho de campo se concentrou em quatro experiências de participação em três Centrais Elétricas localizadas em bairros com contexto crítico em Montevidéu. Da análise emerge que a variedade de sentidos atribuídos às experiências nas Usinas adquirem sentido em relação às trajetórias sociais e às histórias singulares das respectivas práticas artísticas. Em alguns casos as Usinas serviram para complementar e enriquecer um trabalho artístico já desenvolvido, em outros, ao contrário, não foram o instrumento adequado para tornar visível a manifestação em questão. Da mesma forma, a passagem pelas Usinas está relacionada a um processo mais amplo de autoanálise e à experiência de reconhecimento situado.

Palavras-chave: políticas culturais, participação, cultura, direitos culturais

\section{Introducción}

El objetivo de este artículo es describir y analizar experiencias de participación ciudadana en un programa de política cultural de Estado, las Usina culturales. Con este fin partimos de un supuesto general, la reflexión acerca de la política como proceso, no como determinación puramente técnica desde las estructuras sectoriales del Estado, sino considerando cada punto de su desarrollo o cada nivel institucional — con particular atención en la fase en la que los ciudadanos toman contacto con el programa-, como momentos en los que se "hace la política" (GRASSI, 2004). Es decir, como instancias de producción de significados que redefinen y disputan los criterios de implementación, de acceso y las finalidades de la misma. 
En esta dirección, en artículos anteriores, analizamos, por un lado, los paradigmas de política cultural relacionados con la concepción del programa a partir de los documentos oficiales disponibles que lo describen (DUARTE, 2018). Por otro, las prácticas y representaciones de los funcionarios públicos que han participado en su proceso de implementación (DUARTE, en prensa).

El acercamiento de tipo caleidoscópico que proponemos no estaría completo sin la exploración de experiencias de participación que comenzamos a presentar en este estudio. Además de Grassi, trabajos como los de Shore (2010) y Raggio (1997) han señalado la necesidad de enfocarse en cómo las personas le dan sentido a las políticas y a su participación en ellas. Para comprender cómo funcionan las políticas, "necesitamos saber algo sobre cómo son recibidas y experimentadas por las personas afectadas por ellas” (SHORE, 2010, p.29).

En este punto los antecedentes con los que contamos podrían dividirse en dos modos de abordar el análisis de la cuestión. Por un lado, tendríamos el trabajo de Rosalía Winocur que se pregunta por el sentido de cultura que los ciudadanos asocian con las actividades del programa Cultural en barrios, por las funciones que le asignan y por los efectos que perciben de su paso por los mismos (WINOCUR, 1996). Por otro, siguiendo el camino de exploración de raíz anglosajona sobre los efectos sociales de la participación en actividades artísticas (RAMSEY WHITE, RENTSCHLER, 2005), pero desde una postura propia con perspectiva latinoamericana, podríamos ubicar los trabajos de Infantino sobre la participación en artes circenses y la transformación social (INFANTINO, 2008, 2016) y de Mario Roitter en torno a las problemáticas teórico-prácticas que presentan diversas organizaciones artísticas que procuran unir el acceso a múltiples formas de arte con la incidencia en el espacio público (ROITTER, 2009). El trabajo de Paula Simonetti sobre el centro cultural Urbano, pensado fundamentalmente para personas en situación de calle en la ciudad de Montevideo, podría también colocarse en esta línea al cuestionarse sobre las maneras en que la participación artística genera o no nuevas formas de percibirse a sí mismo e impactan en las representaciones que tenemos de los otros (SIMONETTI, 2018).

Como veremos en la primera parte de este trabajo, las Usinas culturales tienen características que las distinguen de los programas culturales que son protagonistas de estos trabajos de referencia. En este punto, es necesario adelantar que, según los documentos de concepción, las Usinas no proporcionan formación artística sino que se proponen como centros de producción cultural. Es decir, proporcionan las herramientas para que las personas concreten un producto. En el caso de las Usinas de música, en las que nos centraremos en este artículo, se trata de poner a disposición un estudio de grabación, un técnico en edición y 
producción de sonido y una sala de instrumentos para que la ciudadanía que participe pueda grabar uno o algunos de sus temas musicales y llevarse un demo. Esto implica que trataremos de personas con una historia vinculada a determinada práctica artística que por distintas razones recurren a la Usina. Nuestro objetivo será explorar cómo influye, si es que lo hace, su pasaje por la Usina en el desarrollo posterior de sus prácticas artísticas y de sus historias de vida.

En esta dirección necesitamos un marco de abordaje que nos permita relacionar las disposiciones y competencias incorporadas, particularmente las relacionadas con las prácticas artísticas, como resultado de los marcos socializadores pasados, y la situación o el contexto de actividad presente. En principio proponemos la arquitectura conceptual del sociólogo Pierre Bourdieu, en particular los conceptos de habitus y campo, para explorar las posibilidades de las prácticas.

Recordemos brevemente que según Bourdieu, los condicionamientos asociados a una clase particular de condiciones de existencia producen habitus, - esquemas mentales y corporales que funcionan como matriz simbólica de las actividades prácticas, conductas, pensamientos, sentimientos y juicios de los agentes sociales. El habitus es, por tanto, lo social incorporado, las condiciones objetivas incorporadas y convertidas en disposiciones duraderas - ("naturaleza socialmente construida" o "historia hecha cuerpo"): maneras de hablar, de caminar, de pensar y de sentir que se presentan con toda la apariencias de la naturaleza (BOURDIEU, 2007).

Asimismo, un "campo" en la sociología de Bourdieu es una configuración relacional de posiciones capaz de imponerse a todos los objetos y agentes que penetran en ella. Cada campo social prescribe sus valores particulares y posee sus propios principios regulatorios (WACQUANT, 1995, p.24).

Las prácticas (ya sea una "elección" alimentaria o de vestimenta, deportiva o política, o un comportamiento cultural o profesional) se comprenden como el resultado de las disposiciones y competencias socialmente construidas (habitus) y las exigencias de un contexto de acción determinado (campo). Para entrar en el juego de cada campo social es necesario un conjunto de disposiciones (habitus) que implica tanto la propensión, inclinación o deseo de entrada como la capacidad de realización o concreción.

Este marco nos permite combinar las representaciones de los actores con otros aspectos de la realidad abordada no dichos o no necesariamente percibidos por ellos, como el peso del pasado incorporado en sus prácticas actuales y las condiciones de funcionamiento de los espacios a los que pretenden acceder. 
Teniendo esto en cuenta nos gustaría hacer algunas consideraciones metodológicas sobre la selección de experiencias que aquí presentamos. Como decíamos más arriba, este artículo forma parte de una investigación más amplia sobre las Usinas culturales de la ciudad de Montevideo inauguradas en la gestión frente a la Dirección nacional de Cultura (DNC) de Hugo Achugar (octubre 2008-marzo 2015), principal actor asociado a la concepción del programa. En nuestras recorridas por cada una de las Usinas estudiadas solicitábamos al técnico en cuestión el registro de las personas que habían participado o, cuando no lo había, los contactos que pudieran proporcionarnos. Con esta información armamos una lista de la que seleccionamos los casos según muestreo teórico. Por motivos de espacio en este artículo presentamos el análisis de cuatro experiencias en tres Usinas ubicadas en barrios de contexto crítico de Montevideo, utilizando como criterios teóricos, en primer lugar, sujetos que hayan vivido en distintas "condiciones de existencia" (BOURDIEU, 2007). Para operacionalizar significativamente esta dimensión elegimos a los entrevistados según compartan o no ciertos determinantes vinculados a situaciones de vulnerabilidad y exclusión social. Dos de nuestros entrevistados, M. y Latin Boy, provienen de hogares descritos como de "bajos recursos", poseen bajo nivel educativo, trayectorias laborales precarias y desvinculación temprana del hogar. Por el contrario, la actriz de teatro y X, provienen de hogares de clase media, poseen nivel educativo medio y alto y trayectorias laborales medianamente estables, aunque no necesariamente vinculadas a su manifestación artística.

Las condiciones de vida no se refieren solo a estas variables (aunque, por supuesto, correlaciona con ellas), sino también a las características de los relatos de los entrevistados al reconstruir su trayectoria vital utilizando como eje sus prácticas artísticas. Así, el consumo problemático de drogas, haber vivido en la calle o tener una educación artística formal desde niño o niña, son rasgos singulares de algunas de estas experiencias que se relacionan directamente con las maneras de vivir una determinada expresión artística.

En segundo lugar, hemos seleccionado prácticas artísticas que si bien podemos abordar con un concepto general de campo, en tanto espacio de posiciones con reglas y valores propios, el campo del teatro infantil, el del rock local, el del canto lírico y el del hip hop (al que podríamos adscribir el beatboxing) tienen distintos grado de institucionalización y por tanto diferentes reglas y requerimientos de entrada y funcionamiento. Si bien no hay estudios específicos al respecto en el medio local, siguiendo a Bourdieu, podemos delinear campos de codificación de ingreso débil y fuerte. Un grado alto de codificación de ingreso va aparejado con reglas del juego explícitas y con un consenso mínimo sobre estas reglas, es decir, con pautas expresas acerca de las habilidades que hay que poseer para entrar al campo 
específico y de las instituciones (instancias de formación, pruebas de acceso, etc.) que las garantizan. Por el contrario, una codificación leve de ingreso es propia de los campos donde las reglas del juego — los criterios de entrada y de apreciación de valor — están en disputa (BOURDIEU, 2002a). En esta dirección, nos propusimos incorporar el campo del canto lírico para explorar las implicancias que una codificación de ingreso fuerte ${ }^{2}$, o más fuerte, podría tener en la experiencia en la Usina.

El trabajo de campo se llevó a cabo durante el año 2016. Combinó entrevistas en profundidad y revisión de registros audiovisuales. Para abordar las experiencias de la actriz de teatro infantil, de X y de $\mathrm{M}$, trabajamos con entrevistas en profundidad. Las entrevistas de la actriz de teatro y de $\mathrm{X}$ se realizaron más de un año después de su paso por la Usina. El tiempo transcurrido nos permitió explorar el recorrido posterior del demo producido en la Usina y las reformulaciones de la experiencia de participación en la Usina asociadas o no al mismo. La entrevista a M. se realizó durante su participación, es decir, M había tenido una sesión en la Usina y cuando lo entrevistamos estaba esperando su segunda visita. Las tres entrevistas fueron realizadas por la investigadora en contextos distintos de la Usina (la casa de uno de los entrevistados y un bar). Si bien el método de análisis podría sintetizarse como análisis del discurso, en nuestras entrevistas, con el fin de achicar la problemática distancia entre el hacer y el decir sobre el hacer, procuramos relevar no solo opiniones — maneras de pensar o representaciones- sino evocar mediante el relato prácticas - maneras de hacer- referidas a situaciones en particular.

El caso de Latin Boy requirió un acercamiento distinto. Dado que no lo pudimos encontrar en el momento del trabajo de campo para entrevistarlo, tuvimos que recurrir a un registro audiovisual realizado por una de las Usinas. A pesar de no haber preparado nosotros la entrevista decidimos incluirla en el análisis porque, compartiendo las condiciones de existencia referidas más arriba para la selección de casos, su relato presenta características que nos obligan a cambiar el foco teórico del análisis y, por lo tanto, a explorar otros aspectos de la realidad estudiada. Los tres entrevistados anteriores declaran su pretensión, independientemente de cual haya sido el recorrido posterior y su análisis, de utilizar las Usinas como un mecanismo de publicación, en el sentido de hacer acceder un objeto y su

${ }^{2}$ Como ejemplo ilustrativo de la codificación de ingreso más fuerte del campo del canto lírico que del resto de los campos tratados en este trabajo, se puede citar la importancia de las instituciones de consagración local, como el SODRE, y los requerimientos de las pruebas de ingreso a la Escuela Nacional de Arte Lírico (prueba de solfeo y de lectura con sus respectivos mínimos exigidos, edad de los aspirantes y prueba de canto donde se ejecuta un aria a elegir entre algunos títulos previstos). Se puede consultar en: https://sodre.gub.uy/escuelas/artelirico 
autor a la existencia pública, conocido y reconocido en un campo dado (BOURDIEU, 2000) y a sus beneficios derivados (como la propia definición de artista, la construcción de trayectorias, de oportunidades laborales, etc.). El relato de Latin Boy, por su parte, no asume un campo para su expresión artística, es decir, no busca reconocimiento de su obra por sus pares, ni oportunidades laborales asociadas a su producción. Esto implica que en las razones desarrolladas para valorar su paso por la Usina subyazca la experiencia de un tipo de reconocimiento que consideramos más cercano a lo planteado por Axel Honnet, en cuanto a las expectativas morales que tienen los sujetos en relación a la sociedad (HONNET, 1997).

De esta manera, el texto se divide en cinco apartados. En el primero se desarrolla la descripción del programa Usinas culturales según los documentos oficiales disponibles y se presenta sucintamente el análisis de los paradigmas de política cultural que lo sustentan. En el segundo se aborda el análisis de la experiencia de participación en la Usina de una actriz de teatro infantil con trayectoria dentro de su campo artístico. En el tercero presentamos dos casos, el de X, cantante lírico, y el de M, cantante de rock, ambos en busca de estrategias de entrada a sus campos respectivos. En el quinto se aborda la vivencia del beatboxing, Latin Boy. El artículo se cierra con algunas conclusiones provisionales.

\section{2. ¿Qué es una Usina cultural?}

En 2005, en un contexto marcado por la crisis de 2002, el Frente Amplio-Encuentro Progresista-Nueva Mayoría asume su primera presidencia en la historia del Uruguay. La victoria electoral de la izquierda uruguaya implicó una renovada atención al sector artístico cultural (KLEIN, 2015) y comenzó a redefinir, desde el Estado, la idea de política cultural que se venía discutiendo desde la academia y la sociedad civil ${ }^{3}$. Uno de los ejes de esta redefinición es el trabajo desde la perspectiva de los derechos culturales, particularmente, la democratización no solo del acceso sino también de la producción de bienes culturales. Bajo estas premisas se modifica la institucionalidad de la DNC creándose en 2009 el Área "Ciudadanía Cultural”, que nuclea distintos programas y proyectos pensados para sectores de la población definidos como vulnerables. En esta órbita institucional funcionan las Usinas culturales.

\footnotetext{
${ }^{3}$ Para profundizar en este punto ver De Torres (2009).

${ }^{4}$ Recordemos que la autoridad máxima en esta materia es el Ministerio de Educación y Cultura, funcionando en su seno distintas unidades con capacidad de decisión para ejecutar un presupuesto propio (CARÁMBULA, 2011). Fue en los primeros años del gobierno frenteamplista que la DNC comenzó a funcionar como una unidad ejecutora más. Sin embargo, para calibrar la dimensión de la DNC es útil el dato presupuestal, según el estudio de la asignación nacional en cultura de Hernán Cabrera, la DNC está en cuarto lugar en cuanto al monto de su presupuesto asignado, después de la Dirección General de Secretaría, el SODRE y la Servicio de Comunicación Audiovisual Nacional (SECAN) (CABRERA, 2018).
} 
La cooperación internacional apoyó y fue protagonista mediante el financiamiento que se le otorgó a ciertos programas del área (KLEIN, 2015). Siete de las primeras Usinas abiertas en el país recibieron apoyo económico proveniente de programas de cooperación internacional.

Actualmente, existen en el Uruguay 18 Usinas, 10 en la zona metropolitana de Montevideo y las restantes distribuidas de manera dispar en el resto del país (DA ROSA, 2018).

Las Usinas culturales son centros de producción audiovisual y musical, en principio, ubicadas en territorios donde existen grandes poblaciones en situación de vulnerabilidad o notorios déficits de infraestructura cultural (por ejemplo, barrios de contexto crítico en Montevideo - Casavalle, Cerro, Carrasco Norte, Bella Italia-, centros penitenciarios -Unidad N 4 Santiago Vázquez, ex COMCAR—, hospitales siquiátricos públicos —Vilardebó— y distintas ciudades del interior del país). En otro lugar, concluíamos que podíamos identificar tres paradigmas de política cultural —-"democracia cultural”, "democratización cultural" y "cultura y desarrollo"- relacionados con la concepción del programa y asociados a los distintos documentos oficiales disponibles en que se describen las Usinas - descripción del programa en la web institucional, documento de presentación producido por la DNC a los cinco años de su gestión y documentos de evaluación producidos en el marco del programa de cooperación internacional "Fortalecimiento de las Industrias Culturales y mejora de accesibilidad a los bienes y servicios culturales de Uruguay"- (DUARTE, 2018). Por razones de espacio, vamos a sintetizar la descripción de los tres paradigmas de referencia 5 . Siguiendo a García Canclini, con "democratización cultural”, nos referimos a un paradigma de distribución y popularización de la cultura legítima justificado en el derecho a la cultura y al rol que la democratización de los bienes simbólicos cumple en la democratización global (GARCÍA CANCLINI, 1987). Si bien este ha contemplado particularmente la universalización del acceso a los productos culturales, también tiene su veta de democratización de la producción o de los productores de cultura, asociada a la formación artística, por ejemplo, las orquestas sinfónicas en barrios de contexto crítico.

A diferencia de las políticas de democratización cultural — ya sean de disfrute o de producción - las de "democracia cultural" parten de la existencia de una pluralidad de definiciones legítimas de cultura. Retomando a García Canclini, ya que no hay una sola cultura legítima, la política cultural no puede dedicarse a difundir solo la hegemónica, sino

\footnotetext{
${ }^{5}$ El desarrollo analítico de este punto se puede consular en Duarte (2018).
} 
que debe promover el desarrollo de todas las que sean representativas de los grupos que componen una sociedad (GARCÍA CANCLINI, 1987). En esta dirección, concretamente en las Usinas se procura evitar en los encuentros entre técnicos y ciudadanos la imposición de un capital cultural sobre otro (SIMONETTI, 2019). Los técnicos deberían facilitar los medios para que "los propios sujetos produzcan el arte y la cultura necesarios para resolver sus problemas y afirmar o renovar su identidad" (GARCÍA CANCLINI 1987, p.50-51). En palabras de Hugo Achugar, "las políticas públicas pasarían a ser, en el mejor de los mundos posibles, la expresión formalizada por parte de un agente neutro, el Estado, de lo propuesto por otro agente, la propia comunidad" (ACHUGAR, 2003, s/p).

El tercer paradigma al que hacemos referencia con la fórmula "cultura y desarrollo", centrado en los sectores audiovisual, del patrimonio natural e intangible y en las tecnologías de comunicación multimedia, relaciona la intervención pública estatal con la producción y difusión cultural doméstica, el pleno empleo, la competitividad, el crecimiento económico y la diversidad cultural (BONET Y NEGRIÉR, 2008). En líneas generales se corresponde con la "tercera generación de políticas culturales" analizada por Rubens Bayardo (2008) y con el trabajo de definición de la cultura como recurso propuesto por George Yúdice (2002).

\section{Dentro del campo. Los artistas}

Comenzaremos por presentar el análisis de la experiencia de grabación en una de las Usinas de una compañía de teatro infantil. En esta dirección, nos parece necesario empezar por abordar la autopresentación de sus miembros recogida de los perfiles que redactaron ellos mismos en la página web de la compañía. En esta exploración nos serán de ayuda las definiciones de "habitus primario" y "habitus secundario". Siguiendo a Wacquant, el habitus primario es el conjunto de disposiciones que se adquiere en la infancia temprana, de manera no necesariamente consciente, a través de inmersión familiar, y que constituye la base y el punto de partida de nuestra "personalidad social", así como "la base para la constitución ulterior de cualquier otro habitus" (WACQUANT, 2014, p.232). El habitus secundario es cualquier sistema de disposiciones adquirido posteriormente, por medio de un trabajo pedagógico que tiene las características de ser: especializado, relativamente acotado en su duración, acelerado en su ritmo, y explícito en su organización (WACQUANT, 2014). Cada agente tiene un habitus primario (genérico), que es a la vez trampolín y matriz para la posterior adquisición de una multiplicidad de habitus (específico). Los miembros de la compañía de teatro comparten en su autopresentación un habitus primario, en cuanto inclinación temprana hacia distintas formas artísticas (canto, baile, actuación, expresión 
plástica), y un habitus secundario, como formación artística específica en distintos grados de institucionalización correspondiente a la oferta existente en Uruguay (no todas las formas de expresión artística tienen en Uruguay la misma posibilidad de aprendizaje formal). Las tres actrices destacan su relacionamiento con niños, trabajan con niños dando talleres y clases de teatro e inglés o estudiando para "Educadora social", además dos de ellas, las que son madres, enfatizan el lugar que distintas formas de arte tienen en el vínculo con sus hijos.

No pretendemos aquí entender el porqué de la dedicación a determinadas formas definidas como arte sino más bien, comprender las características resaltadas en la autopresentación, evitando la "ilusión biográfica" (BOURDIEU, 2002a), como un capital cultural y un conocimiento adquirido. El capital cultural en su estado incorporado se encuentra ligado al cuerpo y supone un trabajo de inculcación y de asimilación. Bourdieu nos recuerda que el trabajo personal, el trabajo de adquisición, es un trabajo del "sujeto" sobre sí mismo (se habla de cultivarse). "El capital cultural es un tener transformador en ser, una propiedad hecha cuerpo que se convierte en una parte integrante de la "persona", un hábitus" (BOURDIEU, 2002b, p.140). Siguiendo a Bourdieu, como anticipábamos más arriba, las disposiciones que constituyen los habitus, entre las que se encuentran las relacionadas con el capital cultural, constituyen la propensión y la capacidad necesarias para entrar en el juego de cada campo social.

En este caso, podríamos hablar del "campo del teatro infantil" como espacio, débilmente institucionalizado, de posiciones y toma de posiciones en las luchas por la definición (MEHL, 2010). Esto se impone desde un primer momento en la descripción en la página web de la principal obra de la compañía, creada en base a cuentos y canciones de María Elena Walsh: "Valoramos especialmente el encuentro con el otro, destacando la ausencia de efectos especiales y la intimidad con el espectador; viviendo el espectáculo como algo inacabado, que cobra sentido y vida con la presencia del público"6.

El espacio que constituye el campo está delineado por un posicionamiento, y una toma de posición, que se construye en relación de oposición a lo que se entiende como "efectos especiales". Espectáculos infantiles montados con varios actores, algunos con vestuario de animales, canciones grabadas, luces "tipo discoteca", etc., generalmente asociados a programas de televisión extranjeros consumidos en la televisión nacional o por televisión por cable como producto para Latinoamérica y con una fuerte presencia de merchandising.

\footnotetext{
${ }^{6}$ http://www.verdeteatro.com/compania.php (28/82020).
} 
En oposición, el eje central de la obra es el canto coral como directriz de la narración, es decir, no hay canciones grabadas, ni banda alguna, se canta a capela y se utilizan algunos objetos e instrumentos para musicalizar. El vestuario es prácticamente blanco, no hay casi maquillaje, excepto un delineado que remarca los ojos, no hay colores estridentes, ni peinados llamativos o voluminosos, ni actores vestidos de animales. Son tres actrices en escena que sacan objetos levemente coloreados de una valija también blanca que utilizan para contar la historia a través de las canciones de María Elena. En algunos momentos se utiliza la luz en la construcción del espacio y se juega con las sombras de las actrices.

Estas oposiciones —íntimo/masivo, minimalista/espectacular, público activo/público pasivo, vocacional/comercial- construyen dos series posibles de correspondencias enfrentados por las que se entreteje este espacio de conflicto: íntimo, minimalista, público activo, incentivo vocacional, contra, masivo, espectacular, público pasivo, incentivo comercial. Estas posiciones anteceden a esta obra en concreto, son posiciones ya instituidas en el marco de la división del trabajo de la producción cultural, a la espera de un habitus socialmente constituido que le predispone de mayor o menor manera a ocupar ese puesto.

En este sentido podemos identificar en los miembros de la compañía los tres componentes del habitus descriptos por Wacquant: cognitivo, conativo y volitivos y afectivos (WACQUANT, 2014).

El componente cognitivo refiere a las categorías de percepción a través de las que los agentes seccionan el mundo, distinguen sus componentes y les otorgan patrón y significado, es decir, no se pertenece a un campo en concreto si no se posee el sistema de clasificación vigente en el mismo. En nuestro caso de análisis este componente estaría presente empíricamente en la serie de posiciones descriptas más arriba.

Ahora bien, el habitus no está constituido sólo de estructuras cognitivas, el componente conativo se relaciona con "las capacidades propioceptivas, habilidades sensomotrices y destrezas cenestésicas que se perfeccionaron en y para la acción útil" (WACQUANT, 2014, p. 233). Estas habilidades o destrezas se diferencian de la inconsciencia y del automatismo reflejo, evidencian una capacidad de generalización y acción que no es asignable a un proceso intelectual representacional sino al cuerpo mismo. Actividades como tocar un instrumento o la danza son muy claras para entender como el cuerpo "entiende" cuál es el próximo movimiento a ejecutar en base al hábito que otorga la experiencia sin transitar un proceso representacional. En nuestro caso, la formación artística de los miembros de la compañía asociada al habitus secundario implica la adquisición de una serie de habilidades artísticas imprescindibles para montar el tipo de obra propuesta. 
Asimismo, para convertirse en un miembro de pleno derecho de un microcosmos dado, no es suficiente ser capaz de interpretar y actuar de acuerdo al uso, también hay que estar afectivamente vinculado a él. En palabras de Wacquant, esto implica que buena parte de nuestra energía mental y de nuestro deseo debe estar involucrado con el campo de referencia, con los objetos y agentes, con las renuncias y las recompensas que allí se ofrecen (WACQUANT, 2014). En nuestro caso es ilustrativo de la "energía vital" investida de la compañía el hecho mantener la obra cuatro años en cartel, incluso en escena en el Teatro Solís, el principal teatro estatal del Uruguay, sin ningún apoyo público ni privado, sustentada exclusivamente a partir de sus propios esfuerzos.

Estos tres componentes son necesarios para que un actor desarrolle el apetito adecuado para las apuestas del juego social correspondiente. En esta dirección Bourdieu sostiene que el habitus lleva a cabo "una estimación de las oportunidades inscritas de manera inmediata en el presente", "cosas por hacer o no hacer, por decir o no decir, en relación con un porvenir probable" (BOURDIEU, 2007, p.87). Este punto dialoga muy bien con la manera en que una de las actrices nos relata el surgimiento del vínculo con la Usina: "surgió la idea, por lo lindo de la obra, ¿qué pasa si esto lo hacemos en formato audio? Y ahí nos empezamos a mover y una amiga dijo que existía esto, de alguna forma escuchó, miramos en la página del MEC y vimos lo que era" (Actriz de la compañía, comunicación personal).

Aquello que se presenta como del orden de lo espontáneo, de lo inmotivado, como estímulos, no existe para la práctica en su verdad objetiva de disparadores condicionales y convencionales, sino a condición de encontrar agentes con las disposiciones necesarias para recocerlos. El habitus por sí solo nunca genera una práctica definida: se necesita de la conjunción de disposiciones y posiciones, capacidades subjetivas y posibilidades objetivas, habitus y espacio social (o campo) para producir una conducta dada o una expresión, "en ese encuentro entre agentes hábiles y un mundo fecundo se incluye la amplia gama que abarca de la felicidad a la tensión, de la suavidad a la aspereza, de lo fértil a lo fútil” (WACQUANT, 2014, p.230).

El disco que se proponen grabar acompaña las tomas de posición descriptas en la obra, en oposición a las obras infantiles comerciales, muchas veces subproductos de programas de televisión, donde las canciones con sus respectivos videos son parte de la oferta, el disco no tiene ni un solo video, es solamente audio.

.... hay que trabajar un poquito para que logren atravesar la barrera de que lo tienen, de que le están dando la imagen y poder entregarse solamente a lo auditivo, para que lo aprendan a disfrutar; porque a veces lo aburrido no es porque es siempre aburrido 
sino porque también no se les mostró nunca otra cosa y la persona no aprendió a disfrutar de eso (Actriz de la compañía, comunicación personal).

Luego de algunas dificultades para comunicarse y malos entendidos de agenda concretaron cita con una de las Usinas:

... grabamos los temas fundamentales, grabamos algunos cuentos y después el resto lo hicimos caseramente, este amigo hizo la mezcla y armó el disco. Lo que nos sirvió de la Usina fue para tener insumos, mucha materia prima para después poder seguir nosotros elaborando el material. Si hacés una canción sola, sí te da el tiempo para que ellos te hagan la grabación y te generen toda la mezcla, digamos, pero un proyecto tan ambicioso como el nuestro no da porque vos vas, creo que fuimos dos jornadas, como cinco horas. Teníamos un límite, nunca pedimos más, sabíamos que a tal hora había que terminar.

La grabación del disco es el producto de un saber hacer, saber cantar, por ejemplo, pero también, de saber leer las posibilidades de la propuesta, "generar insumos", y de un "saber ser", no exigir más tiempo ni trabajo al técnico. Es además el producto de un capital social, en la medida que luego de esas dos jornadas de grabación "el amigo" hizo la mezcla y armó el disco en su casa, con sus equipos.

La utilidad de los lazos que unen a los agentes de un grupo dado es clave para entender la definición de capital social, como conjunto de recursos actuales o potenciales asociados a la pertenencia de una red duradera de relaciones (BOURDIEU, 1980). Esta red les permite mezclar y editar el disco sin que medie ningún rédito económico. Es decir, luego de esas dos jornadas de grabación "el amigo" hizo la mezcla y armó el disco en su casa con sus equipos, teniendo en cuenta que a diferencia de la obra donde el canto es a capela, en el disco se agregan instrumentos musicales a través de la participación de amigos músicos y de la edición. La posproducción del disco requirió mucho trabajo, "porque a nivel auditivo vos tenés que levantar un montón de cosas que [en la obra] vos las das con el cuerpo y con los gestos y en el audio no podés" (Actriz de la compañía, comunicación personal). Este producto les permite presentarse al Fondo Nacional de Música (FONAM), ganar y editar el disco como objeto.

Para finalizar, nuestra entrevistada reflexiona sobre el valor de las usinas: "A nosotros que somos gente que tenemos estudios terciarios, que tenemos no sé qué, que cada uno tiene su trabajo (...) igual nos hubiese sido una demencia ir a grabar (pagando)" (Actriz de la compañía, comunicación personal). En sus palabras se desarrolla una autopercepción de estar en una posición de privilegio, relacionada con los beneficios de una determinada trayectoria 
social que, sin embargo, no proporciona los recursos materiales suficientes como para haber podido financiar estas actividades con sus propios medios. Las Usinas se ven como una política cultural que da respuestas a este tipo de necesidades.

\title{
4. Fuera del campo. Los aspirantes
}

Ahora bien, existen también trayectorias de adquisición de disposiciones, y campos, que tienden a un "mal sentido" de "la inversión a plazo" (BOURDIEU, 2002a), es decir, a una lectura errónea, aquí utilizada en el sentido de autodecepcionante, de la estimación de las oportunidades inscritas en un contexto presente.

En esta dirección podemos leer la experiencia de grabación en una de las Usina de un cantante lírico. X proviene de una familia de emigrantes italianos por el lado materno. Su abuela y su madre cantaban en el ámbito doméstico, no tuvieron una carrera pública debido, según cuenta $\mathrm{X}$, a los prejuicios de esos momentos históricos: "en esas épocas cantar era de prostituta”. Recuerda cantar desde niño, a los 18 años su abuela le dijo:

\begin{abstract}
ya que te gusta la música toma una prueba de canto con mi profesora, sino no servís para esto yo te apoyo para un instrumento, y me probó y me dijo tenés...porque para cantar se nace no se hace, si naciste sin oído no te pueden enseñar, sino no nacés con determinadas cosas no podes, es un don, sino tenés oído fuiste (X Comunicación personal).
\end{abstract}

Pero el don no es suficiente, el canto lírico es una actividad que requiere de un aprendizaje formal continuo. X tomó clases particulares toda su vida pero nunca transitó por los canales locales más institucionalizados de formación (como la Escuela Universitaria de Música o la Escuela de Ópera del Sodre), no accedió a formación en el extranjero, ni a los circuitos locales de presentación de prestigio. Su carrera hasta ese momento incluía presentaciones en el teatro Florencio Sánchez y en liceos públicos en Montevideo. Durante un tiempo estuvo como cantante en la comparsa "Mi Morena", "lo llevó el dueño", Kanela. Nos cuenta que por problemas de relacionamiento con la comparsa su actuación no se prolongó. Se ha dedicado a muchas tareas de subsistencia: "yo hago otros trabajos, me gusta imitar, si tengo que hacer determinadas cosas... dentro de lo legal, porque a mí me educaron con valores" (X Comunicación personal).

A sus 35 años considera que para la ópera no es "ni viejo ni joven". Se acercó a la Usina con la intención de "hacer una grabación, los demos y también que me filmarán, publicarlo en Youtube y mandarlo a Sonic Music Entertainment” (X Comunicación personal). 
(...) al final lo que grabé fueron dos o tres y como vi que...como te puedo decir, para hacer una grabación y para hacerla bien, tenés que estar unas cuantas horas, no por el tema de lo que vos hagas vocalmente sino que tenés que escucharte y tener el oído muy fino, más para lo que yo hago, canto lírico, opera, canzoneta napolitana... (X Comunicación personal)

Como preparación para el día de grabación, $\mathrm{X}$ tuvo que pagar varios ensayos con una pianista, llevar un piano digital y "además ese día estaba con amigdalitis y tenía que grabar o grabar porque si no perdía la fecha” (X Comunicación personal).

De su experiencia en la Usina, resalta la "gran calidad del trato humano" (X Comunicación personal), pero tuvo como punto débil el tiempo con el que se cuenta en la Usina, "a veces que son guachos que no saben ni lo que están haciendo porque vos te estas reventando, estas gastando mucha plata, porque necesitas mucha plata..." (X Comunicación personal).

El tipo de expresión artística que desarrolla $\mathrm{X}$ necesita como preparación una inversión de dinero en ensayos y en traslados de instrumentos, además de un estado óptimo de la voz que difícilmente puede ser predicho y de un tiempo de grabación que excede el ofrecido por las Usinas en una sesión. El tono de decepción implica un mal cálculo, unas expectativas erradas en cuanto a las posibilidades del espacio y de la disponibilidad de los funcionarios que no necesariamente deben estar al tanto de las características de la preparación para una sesión de grabación de canto lírico. El producto no fue el esperado porque el instrumento, las Usinas, no es el óptimo y porque el mismo proyecto parece apuntar a la precariedad de los tres componentes el habitus. Precariedad del componente cognitivo, en la medida que el objetivo "publicarlo en Youtube y mandarlo a Sonic Music Entertainment" no parece tener un conocimiento demasiado acertado de los mecanismos de consagración del campo de canto lírico. Precariedad del componente conativo, en la medida que su trayectoria de formación, habitus secundario, fue por carriles disímiles a los circuitos más legítimos; y precariedad del componente afectivo, dada la dispersión de su interés y de su deseo.

Asimismo, existen trayectorias sociales, que aunque puedan identificar las posibilidades de las Usinas como mecanismo de publicación válido en el campo en cuestión, no contribuyen a la acumulación de capital específico. Por ejemplo, detengámonos en otra experiencia, la de M. En su autopresentación M. relata:

Hago música desde los 15 años, ahora tengo 36. Soy tercera generación de guitarreros, yo no estudié música, soy autodidacta, mi abuela y mi viejo tocaban. Aprendí con mi padre, él tocaba folklore, empecé por ahí y después mucho rock, pasé por la bossa nova y yo a los 15 años me fui a vivir..., dejé de trabajar, me compré una guitarra y ta empezó mi carrera de adicto también. Larga carrera de adicción pero hace tres años estoy mejor porque ta yo compre el modelo que para 
ser buen músico había que encajarse como Charly García, los Doors, Janis Joplin. Mis referentes eran en parte el Príncipe y Mateo. Yo compré ese modelo y me pareció que era esa que para hacer rock había que encajarse, pero ta, es un poco así, pero la realidad es que yo no morí a los 27 y muchos problemas, muchos problemas sicológicos también tuve una esquizofrenia (M. Comunicación personal).

M. elige dos elementos claves para representar su relación con la música: su familia y el consumo de drogas. El primero de ellos puede ser leído en términos de capital cultural. M. es tercera generación de guitarreros. Su vínculo con la música es fruto de un aprendizaje informal, en el seno familiar — su abuela y su padre-. Ésta descripción posee las características del modelo de incorporación de capital cultural que trabaja Bourdieu: transmisión por vía hereditaria que suele pasar inadvertida. Como decíamos más arriba, el capital incorporado es una posesión que se ha convertido en parte integrante de la persona, en habitus. "Del tener ha surgido ser" (BOURDIEU, 2002b, p.140): un guitarrero.

Siguiendo con Bourdieu, la incorporación de capital cultural requiere una inversión de tiempo, "uno invierte tiempo, pero invierte también una forma de afán (líbido) socialmente constituido, el afán de saber (libido sciendi)" (BOURDIEU, 2002b, p.139). Ahora, si bien la incorporación de capital cultural específico en el ámbito familiar tiene efectos vitalicios en el cuerpo, por ejemplo en los acentos con los que hablamos o en los ademanes con los que nos expresamos, la prolongación del tiempo de apropiación es clave para entender la reconversión del capital, por ejemplo, en capital económico o simbólico (posibilidades de trabajo o de reconocimiento, en este caso asociadas a la música). En este sentido, siguiendo a Bourdieu, un individuo sólo puede prolongar el tiempo destinado a la acumulación de capital cultural mientras su familia pueda garantizarle el tiempo libre y liberado de la necesidad económica (BOURDIEU, 2002b).

En este punto nos gustaría integrar el segundo elemento de referencia, el consumo de drogas. Siguiendo su relato, la música se asocia a un estilo de vida "contracultural" donde las drogas tienen un protagonismo central. Para explicarnos esto, cita a distintos referentes del mundo del rock pertenecientes a diferentes lugares geográficos e históricos, pero que en su discurso están unidos por la experimentación con drogas como vía a una producción musical de mayor autenticidad.

A los 15 años, deja de trabajar, se compra una guitarra y comienza a experimentar con drogas. Siguiendo su relato, vive intermitentemente en la calle, hasta el año 2008, donde nos cuenta que tuvo lo que él define como un ataque de paranoia. A raíz del mismo estuvo dos años viviendo en una "casa de salud, totalmente empastillado". Después de esos dos años “empecé a consumir otra vez y logré que me bajaran la medicación y ta me echaron de esa 
casa de salud y ahí como que volvía a estar en la calle o en lo de mi vieja" (M. Comunicación personal).

La conjunción de su situación económica y su "carrera de adicto" configuran un trayecto biográfico que no contribuye a generar los espacios de tiempo necesarios para prolongar la adquisición de capital cultural que está en la base de la construcción del "talento" (BOURDIEU, 2002b). A su vez, tampoco habilitan el tipo de contacto que necesita el establecimiento de lazos asociados al capital social.

Me fui a vivir a la casa un músico, un músico que tocó con los mejores pero vivía muy mal, vivía en la mierda en una casa que le habían dejado los padres, vivía en la mugre. Ahí volví a tocar, antes de la recaída. En el auge me compre un cajón peruano, éramos tres amigos le pusimos "piso doce" a la banda pero ta después lo terminé vendiendo y ta todo mal de vuelta (M. Comunicación personal).

Del relato de $M$. podemos inferir que en algunos momentos tenía contacto medianamente estable con músicos reconocidos, sin embargo, las necesidades materiales y sobre todo las necesidades económicas vinculadas a sostener el consumo de drogas, no permite generar y menos reconvertir, en los términos del campo musical, los beneficios derivados de pertenecer a este grupo.

A partir del año 2012 comienza a mantenerse alejado de manera sostenida del consumo de drogas ilegales: "Ahí me di cuenta que la música me surgía sola, que no precisaba consumir, la música está dentro mío, es como una necesidad que tengo de hacerla, es lo que me gratifica más, me calma el alma. Me hace sentir más feliz" (M. Comunicación personal).

Insistimos en la idea del capital cultural incorporado en los primeros años de vida como parte integrante de la persona, M. es un guitarrero, hacer música lo hace sentir mejor, "lo hace más feliz", sin embargo, que otras personas escuchen sus creaciones es una vivencia con características distintas. Cuando M. tocaba arriba de los ómnibus le parecía que la gente no lo entendía: "me puse bastante pedante y egocéntrico, veía a la gente: ¡qué canta este pibe por favor!, veía a la gente que se agarraba, cuando cantaba covers no, cuando cantaba covers la gente los toleraba mejor pero cuando cantaba mis temas, nadie los entendía..." (M. Comunicación personal).

La oposición entre covers y sus temas estructura el rechazo o la incomprensión pública que siente M. cuando canta su música, aquella que crea poniendo todo de sí mismo frente a la música de los otros que él solamente reproduce. 
El antes y el después del consumo es también un antes y un después en la manera en que vive la recepción pública de su música. Si M. en el "antes”, describe su reacción frente al sentimiento de rechazo e incomprensión, a través de la agresividad, el egocentrismo y la pedantería, el "después”, la sobriedad, está marcado por el miedo y la inseguridad: "yo lo quería hacer siempre de la manera más loca y después me di cuenta que tengo que ir más por la Usina cultural, presentándome en boliches pero realmente a veces me agarra unos miedos. Me da miedo, me da miedo..." (M. Comunicación personal).

En particular con la música, en el miedo de M. se traduce la inseguridad de tener que relacionarse de una manera nueva con la gente que lo escucha. En este sentido, su paso por la Usina le aporta un elemento clave de cuestionamiento, M. nunca se había escuchado cantar en una grabación, “era la primera vez que grababa, igualmente me falta mucho... yo no sé cantar, el técnico de sonido hizo lo máximo pero igualmente hay detalles...yo no estoy para cantar...” (M. Comunicación personal).

Escucharse cantar lo hizo revisar experiencias pasadas, por ejemplo, si la incomprensión y el rechazo que experimentaba en los ómnibus no tendría que ver con su canto, "yo tengo la voz muy grave también y quiero ir arriba y me exijo mucho y quedaba afónico a las dos o tres canciones. Era desastroso jajajaj [se ríe]" (M. Comunicación personal).

Lo hizo también replantearse su propia forma de relacionarse con la música, más concretamente la manera en que sus composiciones responden a la imagen sobre sí mismo que intenta volver a crear:

La música es algo sublime, hoy pienso que la música es un lenguaje que preferiría hacer instrumental porque me doy cuenta que genero malos estados emocionales y eso me puede volver a mí, entonces digo es mejor no hablar a veces... pero tampoco soy tan bueno como para hacer música instrumental (M. Comunicación personal).

Por último, escuchar su voz grabada en la Usina, lo hace cuestionarse sobre la viabilidad de su proyecto, una vez haya llegado a redondear un demo: "Yo pensaba dejarlo en boliches y tocar...pero antes me tengo que sentir bien yo (...) ta, tengo que seguir tomando [la medicación] y relacionarme con otra gente pero ta, todo me requiere mucho esfuerzo" (M. Comunicación personal).

Hasta el momento de nuestro último encuentro M. está inmerso en un proceso terapéutico que tiene como uno de sus componentes la introspección. Una de las claves de su reflexión sobre sí mismo es poder reformularse como sujeto en estas nuevas condiciones, sin el consumo de drogas ilegales, pero aceptando un estado anímico o emocional asociado a la 
medicación que aunque de alguna forma vive como no propio, no perteneciente a su ser, es el camino para "sentirse bien". La relación con la música, al ser un elemento central en la construcción de su singularidad individual, es también parte de este proceso de recreación subjetiva, pero como vimos en su relato, esta transformación está lejos de ser aproblemática, antes bien, la tensión, los miedos y las inseguridades son característicos de este trabajo sobre sí mismo.

El rol de las Usinas en esta experiencia aparece, en primer lugar, descripto en el marco de una serie de caminos legítimos ("ir más por la Usina” dice en la cita referida más arriba en contraposición a "hacerlo de la manera más loca") de los que se espera los beneficios de seguir el camino de lo razonable ("llevar el demo", "tocar en boliches"). Sin embargo, M. no ha podido realizar una acumulación de capital cultural ni social, su trayecto biográfico no le ha permitido trabajar sobre su voz, sobre su forma de cantar, ni le ha permitido seguir desarrollando sus habilidades instrumentales. En este marco, su paso por la Usina se transforma, ya no es una herramienta que lo vincularía con cierto circuito musical sino una clave para cuestionar su relación con la música y consigo mismo. Su participación en la Usina forma parte de un proceso más fundamental de cuestionamiento de su habitus, contribuye a una suerte de autoanálisis. Wacquant nos recuerda que el habitus en los casos que incorpora disposiciones reflexivas (en la experiencia de M. a través de distintos discursos terapéuticos) y en la medida en que estas disposiciones son aplicadas a los propios pensamientos, sentimientos, acciones y entorno del agente, puede guiar una forma de auto-trabajo (WACQUANT, 2014b). Es necesario subrayar que las Usinas no son autosuficientes en este sentido, contribuyen a la reflexión sobre sí mismo en la medida que están inmersas en un proceso más amplio y de mayor continuidad en el que en la experiencia de M. participan diversas instituciones públicas.

\section{Sin campo: los artistas profanos}

Latin Boy trabajaba doce horas de limpiador de vidrios en el shopping de Punta Carretas. Es afrodescendiente, no llega a los 30 años de edad. Se acercó a la Usina a través del Centro Cultural Urbano. Lo invitaron en un Refugio al que fue a pasar la noche. En ese momento estaba desvinculado de su familia e inmerso en las vicisitudes del consumo problemático de drogas.

El beatbox lo acompaña todo el día. Interrumpe sus tareas para hacer música en cualquier momento que puede, incluso más, hace música mientras limpia los vidrios. "El 
beatbox ${ }^{7}$ nace contigo, nace porque en un momento a alguien de tu familia le encantaba el rap. Eso nace de géneros, si me preguntas como lo siento, lo siento como una parte mía que no la puedo dejar, yo lo aprendí, me salió a raíz de la calle” (Latin Boy. Audiovisual realizado en la Usina del $\mathrm{Cerro}^{8}$ ).

Las propias características del beatboxing lo hacen compatible con su estilo de vida, no necesita instrumentos musicales (ni el dinero para conseguirlos y el tiempo para cuidarlos), ni un tiempo específico de ensayo (en el sentido que la práctica es, en su caso, compatible con otras actividades simultáneas), ni socializar con otras personas que se interesen y hagan música. Tampoco necesita de un aprendizaje formal, aprendió por contacto directo en su núcleo familiar.

\begin{abstract}
Los sonidos y la música van sonando en tu cabeza, van sonando de una manera que son como no sé, como algo que no lo podés sacar nunca como que siempre...por ejemplo: estás pensando que tenés que pagar una cuenta y tenés dos semanas todavía para cobrar. Viene a ser algo así, eso está y no te lo podes sacar de encima, está ahí, están juntos, son uno, van juntos, con ese ritmo vas a todos lados (Latin Boy. Audiovisual realizado en la Usina del Cerro).
\end{abstract}

La cita da cuenta de cómo se relaciona con su forma de expresión estética. Los términos que elige para caracterizar este vínculo no son relativos, son afirmativos. Es decir, a diferencia, por ejemplo, del teatro infantil — definido en la contraposición con el teatro infantil comercial - o el rock de M. —entendido como auténtico en oposición a aquello que no lo es-, Latin Boy describe su música como un vínculo consigo mismo. No hay referencias a lo que llamamos, siguiendo a Wacquant, componente cognitivo del habitus, a pesar de haberse dedicado al beatboxing gran parte de su vida, no hay referencias al sistema de clasificación propio del campo específico. El componente conativo está presente de manera muy fuerte en este tipo de expresión artística donde el cuerpo es el propio instrumento de producción musical, pero aunque se menciona un "familiar que le gusta el rap", y que nos remite a una socialización temprana, la incorporación de las habilidades necesarias para el beatbox está presentada como del orden de lo innato, pertenecen a la naturaleza de su ser: "Eso está ahí y no te lo podés sacar de encima, son uno y con ese ritmo vas a todos lados" (Latin Boy. Audiovisual realizado en la Usina del Cerro).

\footnotetext{
7 El beatboxing es un estilo de percusión vocal originado en la cultura del hip-hop de los años ochenta, particularmente en Nueva York. Consiste en la imitación vocal de cajas de ritmos, así como tambores y otras percusiones, y la imitación simultánea de bajos, melodías y voces, para crear una ilusión de música polifónica. Se puede realizar a capela o con amplificación (STOWELL y PLUMBLEY, 2008).

${ }^{8}$ https://www.youtube.com/watch?v=2hWXMsoCCYE
} 
Por último, esta simbiosis entre el sujeto y el objeto hace imposible identificar un componente afectivo, tal cual lo define Wacquant, en la medida que no se puede hablar de dirección de las energías o del deseo en los objetos o agentes, con las premios y decepciones que le son inherentes, sino se vivencia la separación entre sujeto y objeto.

La falta del componente afectivo y de la noción de interés para describir el vínculo con su arte - por ejemplo, no se refiere a ser recocido o a forjar una trayectoria profesional— se relaciona con la ausencia del concepto de campo para dar cuenta de su experiencia de creación estética. Varios autores, entre ellos el propio Wacquant y Bernand Lahire, han enfatizado la premisa de que no todo contexto pertinente de actividad para el análisis de las prácticas responde necesariamente al concepto de campo. Los campos entendidos a la manera de Bourdieu, no iluminan las escenas cotidianas, las actividades temporales o las prácticas amateurs que no conllevan necesariamente un posicionamiento o reconocimiento de las reglas inmanentes al campo, o, en su defecto, no son asignables a ningún campo en particular por no estar organizadas sistemáticamente en la forma de espacios de posiciones de lucha entre los diferentes agentes (LAHIRE, 2003).

Ahora bien, siguiendo la lógica de las prácticas desplegada hasta aquí podríamos decir que Latin Boy no ha incorporado en su habitus los esquemas que sirven para producir las prácticas adecuadas a un campo determinado ni el interés para jugar el juego. En este sentido, la descripción de su vínculo con la creación (plena — no relacional- y desinteresada en cuanto a sus posibles retribuciones materiales y simbólicas) puede ser leída como producto de la incorporación de sus condiciones objetivas.

La ausencia de participación en un campo, el del hip hop local, por ejemplo, sería, en esta perspectiva, el resultado del ajuste entre las condiciones objetivas y el habitus, "necesidad hecha virtud", no habría noción de campo ni interés de participación en su vivencia porque sus condiciones objetivas no habilitaron la adquisición de estas disposiciones. Ahora bien, en vez de cancelar la discusión con la constatación del ajuste entre condiciones objetivas y habitus, nos gustaría abrirla mediante la incorporación de herramientas analíticas que nos permitan abordar la plenitud del discurso, es decir, no aplanarlo o directamente excluirlo sino retomar sus aspectos afirmativos en su densidad semántica.

La relación de Latin Boy con el beatbox es descripta como un momento de inmersión en la forma de expresión que no deja lugar a nada más, no hay espacio para el cálculo — de lo que el beat vox le da o le podría dar, en ningún término, ni espiritual, ni material—, no hay espacio para el juicio, es un estado de entrega sin demandas ni justificaciones, de presente puro. Recurriendo al vocabulario que utiliza el sociólogo Luc Boltanski podríamos definirlo 
como un estado de ágape (BOLTANSKI, 2000). A través del análisis y la comparación con las nociones de philia y eros, Boltanski propone la noción de ágape como la anulación de las equivalencias presentes en la reciprocidad de la philia y en la posesión característica del eros: al no darse como imperativo el ser proporcional en mérito a aquel se dirige, el ágape no tiene necesidad de recurrir a un patrón de valor. Es por esto que ignora el cálculo, "las personas en estado de ágape no acumulan más que para el día presente y no se preocupa por el mañana" (BOLTANSKI, 2000, p.166). El amor ignora el deseo de conocer y permanece sin réplica. Solo la práctica lleva a su término la explicación reuniéndola con el ser. Instalado en la permanencia, es decir, siempre reinstalado en el presente el amor está al abrigo de la angustia porque ya no calcula ni plantea la cuestión del cambio (BOLTANSKI, 2000).

Ahora bien, para Latin Boy su vivencia en el Centro cultural Urbano fue central no solo para entrar en contacto con la Usina sino para entender el desarrollo de su paso por la misma. Fue en Urbano que experimentó una suerte de renacimiento de su humanidad asociado al reconocimiento y valorización de su expresión artística:

Yo llegue un día a urbano porque me invitaron de un refugio, yo estaba separado de mi familia y llegue ahí a Urbano y me enseñaron, me enseñaron no, me hicieron sentir que yo realmente era una persona, que yo era esa luz que realmente quería brillar, que quería brillar ahí, que quería hacerles ver que tenía algo guardadito ahí que de tanta depresión que tenía no lo podía sacar (Latin Boy. Audiovisual realizado en la Usina del Cerro).

En este marco le propusieron acercarse a la Usina. Cuando llegó, Latin Boy no tenía muy claro qué iba a pasar. Primero grabó en la sala de audio. Luego fue protagonista de un corto audiovisual con su música y algunos trozos de su historia. En este proceso pudo terminar de imaginarse que buscaba con esta experiencia:

Me gustaría cumplir mi sueño para poder ayudar a mis hijos, eso es lo que tanto deseo, y más nada, mostrarle al mundo que el cuerpo es mágico y que solamente se logra algo, se puede tener algo, si se lucha en la vida, si miras hacia atrás y decís yo puedo con esto, yo puedo remar con esto (Latin Boy. Audiovisual realizado en la Usina del Cerro).

El lenguaje del ágape que utilizamos para entender el vínculo con su arte no es pertinente para describir sus deseos y aspiraciones asociados a los mecanismos de publicación, de hacer público su arte a través de los dispositivos de la Usina. Recordemos que Latin Boy pasa la mayor parte de su tiempo en la vía pública, trabaja y vive en la calle, su performance de beatbox es frente a la vista de los otros, sin embargo, en su relato no se incorpora la mirada de los otros en la manera de describir su vivencia artística hasta su paso 
por la Usina. Es en Urbano y luego en la Usina que su práctica de beatbox empieza a ser contada como una capacidad, una aptitud, una habilidad que necesita ser reconocida.

Ahora bien, las pretensiones de Latin Boy asociadas al reconocimiento no tienen que ver directamente con conseguir trabajo como músico o ser reconocido como artista, sino que se refieren a un movimiento más fundamental, al reconocimiento de su humanidad. Siguiendo a Honnet, el reconocimiento es el elemento fundamental de constitución de la subjetividad humana, en la medida que el ser humano sólo se constituye como tal en relación con otros seres humanos en un medio intersubjetivo de interacción. En el plano de los individuos, la ausencia o falta de reconocimiento, o el mal reconocimiento o reconocimiento fallido, se constituirá como el principal daño a la subjetividad de las personas (HONNET, 1997).

En su experiencia, la valoración de su expresión artística no se asocia con cambios en su situación material sino con la autoafirmación como sujeto. La mirada positiva de los otros se transforma en una mirada positiva sobre sí mismo, lo hace "sentir que era una persona", "esa luz que quería brillar". Recordemos que Honnet divide las formas de reconocimiento en tres esferas: el amor, el derecho y la valoración o solidaridad social con sus respectivas formas de menosprecio, maltrato y violación, desposesión de derechos y exclusión e indignidad e injuria.

La esfera del amor surge de la relación primaria entre la madre y el niño, centrada en los componentes físicos y psíquicos para el desarrollo de los individuos. Por su parte, en la esfera del derecho se expresan los derechos universales, es decir, los seres humanos se reconocen como fuente de deberes y derechos independientemente de toda caracterización de orden social, económica o cultural. La esfera del derecho se diferencia de la valoración social en su particularismo, mientras que la esfera del derecho es universal, la de la valoración social reconoce las particularidades del sujeto, sus singularidades según ciertos “estándares socioculturales" (HONNET, 1997, p.158).

La experiencia de valoración social va unida a una seguridad sentida de poder realizar operaciones o de poseer capacidades que son reconocidas por los demás miembros de la sociedad como valiosas. "Tal tipo de autorrealización práctica podemos llamarla con los conceptos de autoconfianza, autorrespeto o autoestima" (HONNET, 1997, p.158). Su contrario, el menosprecio social, implica en esta esfera lesionar las posibilidades de autorrespeto singular o colectivas. Honnet sostiene que el status de una persona designa la medida de la valoración social que una sociedad otorga a un determinado tipo de autorrealización. La jerarquía social de valores ordena las formas singulares de vida o los modos de convicción como menos válidos que otros, para luego sustraer a los sujetos 
concernidos toda posibilidad de atribuir un valor social a sus propias capacidades. La experiencia de tal desvalorización conlleva pérdida de autoestima personal y obstaculiza la oportunidad de poder entenderse como un ente estimado en sus capacidades y cualidades características (HONNET, 1997).

Ahora bien, es importante observar que el proceso de reconocimiento vivido por Latin Boy es situado, es decir, se vivencia asociado al microcosmos institucional que constituye el centro cultural Urbano y la Usina. Por fuera se encuentra "el mundo", ese tercero que aún no forma parte de esta experiencia de reconocimiento, al que Latin Boy alude con "hacerles ver", y al que hay que "mostrar", incluso para ayudar a sus hijos, que "yo puedo con esto", "yo puedo remar con esto".

En este sentido, la experiencia de reconocimiento individual vivida dentro de este microcosmos singular, aunque puede vincularse conceptualmente a la valoración social tematizada por Honnet, no es inmediata ni necesariamente extrapolable al mundo. El mundo se mantiene como un lugar ajeno, al que hay que demostrarle que uno es una persona.

\section{Conclusiones}

En el desarrollo de este artículo surgen una variedad de sentidos atribuidos a las experiencias en las Usinas. En algunos casos las Usinas sirvieron para complementar y enriquecer un trabajo artístico que ya se venía desarrollando, en otros, por el contrario, no resultaron la herramienta adecuada para visibilizar la manifestación artística en cuestión. Asimismo, relacionamos el pasaje por las Usinas con un proceso más amplio de autoanálisis en la experiencia de M. y con la vivencia de un "reconocimiento situado" en la de Latin Boy. En esta dirección, los sentidos atribuidos a las Usinas adquieren significado en relación a las trayectorias sociales y a la historia de las experiencias singulares de las prácticas artísticas respectivas.

Si ensayamos una puesta en relación de estas vivencias con los paradigmas de política cultural asociados a los documentos de concepción, podríamos decir, en primer lugar, que las Usinas no siempre serían útiles como herramientas de democratización cultural, ya que hay campos de la cultura legítima — como el del canto lírico- para los cuáles no resulta la herramienta adecuada para la grabación, ni es pertinente como mecanismo de visibilización y consagración.

En segundo lugar, la serie de causalidades, del tipo grabar un demo, hacerlo circular en distintos lugares y generar así oportunidades de visibilidad del producto e incluso de ingresos materiales, asociadas al paradigma "cultura y desarrollo", está relacionada, por un 
lado, a condiciones de vida que hayan permitido una dedicación continuada a la formación artística y una acumulación de capital social necesario como habilitador y, por otro, a expresiones artísticas organizadas en campos poco institucionalizados, como el del teatro local infantil, con mayor porosidad para admitir mecanismos de visibilización.

En tercer lugar, el autoanálisis y las experiencias de reconocimiento vinculadas a lo que llamamos democracia cultural, no deben ser experiencias abordadas desde un punto de vista aproblemático. Es decir, los procesos empíricos de autoanálisis que pueden favorecer las Usinas en tanto programas de política cultural, no necesariamente redundan en la resolución de problemas o en la afirmación identitaria, sino que tienen consecuencias inciertas para la integridad personal. De la misma manera, la experiencia de reconocimiento en nuestro trabajo se ha mostrado situada y no necesariamente extrapolable a un sentimiento de valoración de la sociedad en su conjunto.

Para finalizar, la política cultural no es una varita mágica, que transforma inmediatamente la realidad en un sentido inequívoco o fracasa. Siguiendo a Merklen y Filardo, en las políticas no solo hay ejecutores y beneficiarios sino sujetos con historia y con agencia que participan de entornos sociales que los condicionan (MERKLEN y FILARDO, 2019). Sus apropiaciones del espacio que abre la política, configuradas por y en las características de la vida social en la que se desenvuelven, son la política encarnada y constituyen un objeto fundamental de investigación para comprender su funcionamiento y posibles contribuciones.

\section{Referencias}

ACHUGAR, H. Derechos culturales: ¿una nueva frontera de las políticas públicas para la cultura? Pensar Iberoamérica. Revista de cultura, n.4, 2003. Disponible en: https://www.oei.es/historico/pensariberoamerica/ric04a04.htm. Acceso en: 2 de set. 2020.

BAYARDO GARCÍA, R. Políticas culturales: derroteros y perspectivas contemporáneas. Revista de Investigaciones Políticas y Sociológicas (RIPS), v. 7, n.1, p.17-29, 2008. ISSN 1577-239X. Disponible en: https://www.redalyc.org/pdf/380/38070103.pdf.Acceso en: 2 de set. 2020.

BOLTANSKY, L. El amor y la justicia como competencias. Tres ensayos de sociología de la acción. Tres ensayos de sociología de la acción. Buenos Aires: Amorrortu, 2000.

BONET, L,, NÉGRIER, E. Conclusion générale. La fin des cultures nationales? En: BONET, L, NÉGRIER, E (coords.). La fin des cultures nationales? Les politiques culturelles à l’épreuve de la diversité, France-Quercy á Mercuès: La Découverte/Pacte Grenoble, 2008. 
BOURDIEU, P. Le capital social. Actes de la recherche en sciences sociales, v 31, p.2-3 1980. Disponible en: https://www.persee.fr/issue/arss_0335-5322_1980_num_31_1.Acceso en: 3 de set. 2020 .

Una revolución conservadora en la edición. En: BOURDIEU, P. Intelectuales, política y poder. Buenos Aires: Eudeba, 2000.

Poder, derecho y clases sociales. Bilbao: Desclée De Brouwer, 2002.

Las reglas del arte. Génesis y estructura del campo literario. Barcelona:

Anagrama, 2002.

El sentido práctico. Buenos Aires: Siglo XXI, 2007.

CABRERA, H. ¿Qué lugar ocupa la cultura en el Presupuesto Nacional? Un breve análisis descriptivo de la evolución de la asignación presupuestal en cultura 1999-2018. Cuadernos del Claeh, v. 37, n.107, p. 131-158, 2018. ISSN 2393-5979. Disponible en: https://publicaciones.claeh.edu.uy/index.php/cclaeh/article/view/348. Acceso en: 3 de set. 2020.

CARÁMBULA, G. La institucionalidad cultural publica como problema. En: AROCENA, F. (coord.) Regionalización cultural del Uruguay. Montevideo: MEC, 2011.

DA ROSA, E. (2018). Más allá del demo y el ensayo: estudio del alcance del programa Usinas Culturales. Cuadernos del Claeh, v, 37, n. 107, p. 285-299, 2018. ISSN 2393-5979. Disponible en: https://publicaciones.claeh.edu.uy/index.php/cclaeh/article/view/336. Acceso en: 2 de set. 2020.

DUARTE, D. Pensando la participación en las Usinas Culturales desde sus destinatarios. Encuentros latinoamericanos v.2, n. 1, p.3-17, 2018. ISSN 1688-437X. Disponible en: https://ojs.fhce.edu.uy/index.php/enclat/article/view/73/81. Acceso en: 1 de set. 2020.

DUARTE, D. Las Usinas Culturales de Montevideo desde la perspectiva de los funcionarios públicos participantes en su proceso de implementación. Papeles de trabajo (EN PRENSA)

GARCÍA, CANCLINI, N. Políticas culturales y crisis de desarrollo: un balance latinoamericano. En: Néstor García Canclini (ed.) Políticas culturales en América Latina, Mexico D.F: Grijalbo, 1987.

GRASSI, E. Problemas de la teoría, problemas de la política, necesidades sociales y estrategias de política social. Revista Lavboratorio. Estudios sobre Cambio Estructural y Desigualdad Social, v.6, n. 16, p.6-12, 2005. ISSN-e 1852-4435. Disponible en: https://publicaciones.sociales.uba.ar/index.php/lavboratorio/issue/viewIssue/Lavboratorio\%20 N\%C2\%B0\%2016\%20Verano\%202004\%202005/139. Acceso en: 1 de set. 2020.

HONNET, A. La lucha por el reconocimiento. Por una gramática moral de los conflictos sociales. Barcelona: Grijalbo, 1997. 
INFANTINO J. El arte como herramienta de intervención social entre jóvenes en la ciudad de Buenos Aires. La experiencia de "Circo Social del Sur". Medio Ambiente y Urbanización, v. 69, n.1, p. 35-54, 2008. ISSN 0326-7857. Disponible en: https://www.ingentaconnect.com/content/iieal/meda/2008/00000069/00000001/art00004\#.

Acceso en: 1 de set. 2020.

De pluralizar las políticas culturales al arte para la transformación social. En: Cardini, Laura y David Madrigal González (coords.) Cultura, antropología y transformación social desde las políticas culturales de Argentina, Brasil y México. México: El Colegio de San Luis de Potosí, S. C. (En prensa).

KLEIN, R. Políticas culturales y descentralización territorial en Uruguay. Políticas Culturais em Revista, v 1, n.8, p. 76-90, 2015. ISSN: 1983-3717 Disponible en: https://rigs.ufba.br/index.php/pculturais/article/viewFile/13459/9749. Acceso en: 1 de set. 2020.

LAHIRE, B. Campo, fuera del campo, contracampo. En LAHIRE, B. (coord.) El trabajo sociológico de Pierre Bourdieu, deudas y críticas. Buenos Aires: Siglo XXI, 2005.

MEHL, R. El teatro para niños y sus paradojas: reflexiones desde la platea. Buenos Aires: Inst. Nacional del Teatro, 2010.

MERKLEN, D., FILARDO V. Detrás de la línea de pobreza. La vida en los barrios populares de Montevideo. Buenos Aires: Gorla. 2019

RAGGIO, L. El enfoque antropológico en el estudio de las políticas sociales posibilidades y limitaciones. En: Ponencia V Congreso de Antropología Social. Universidad de La Plata. Julio-agosto 1997, La Plata. Disponible https://antrosocial.files.wordpress.com/2014/05/raggio-liliana_el-enfoque-antropolc3b3gicoen-el-estudio-de-las-polc3adticas-sociales.pdf. Acceso en: 1 de set. 2020.

ROITTER, M. Prácticas intelectuales académicas y extra-académicas sobre arte transformador: algunas certezas y ciertos dilemas. Centro de Estudios de Estado y Sociedad. Disponible en: http://repositorio.cedes.org/handle/123456789/3758. Acceso en: 1 de set. 2020.

SIMONETTI, P. ¿La cultura hace bien? Políticas culturales dirigidas a sectores vulnerados y organizaciones sociales en el Uruguay (2007-2017). 2018. Tesis de Maestría (Maestría en sociología de la cultura y análisis cultural) Instituto de Altos Estudios Sociales. Universidad Nacional de San Martín. 2018

Políticas socioculturales en Uruguay la cultura como medio como fin, como derecho ¿Qué piensan los gestores?. Políticas Culturais em Revista, v.12, n. 1, p. 284-306, 2019. ISSN: 1983-3717 Disponible en: https://portalseer.ufba.br/index.php/pculturais/article/view/29246. Acceso en: 1 de set. 2020.

SHORE, C. La antropología y el estudio de la política pública: reflexiones sobre la "formulación" de las políticas. Antípoda. Revista de Antropología y Arqueología, n. 10, p. 2149, 2010. ISSN: 1900-5407. Disponible 
https://revistas.uniandes.edu.co/doi/pdf/10.7440/antipoda10.2010.03. Acceso en: 1 de set. 2020.

STOWELL, D., PLUMBEY, M. Characteristics of the beatboxing vocal style. Technical Report, Dept. of Electronic Engineering, Queen Mary, University of London, Centre for Digital Music C4DMTR-08-01. Disponible http://c4dm.eecs.qmul.ac.uk/papers/2008/Stowell08-beatboxvocalstyle-C4DM-TR-08-01.pdf. Acceso en: 3 de set. 2020.

TORRES DE M. I. Cultura, diseño institucional y prácticas democratizantes: algunas reflexiones. En: Institucionalidad cultural. Montevideo, MEC/DNC, 2009.

WACQUANT, L. Introducción. En BOURDIEU P. y WACQUANT, L. Respuestas: por una antropología reflexiva. México: Grijalbo, 1995.

WACQUANT, L. Homines in extremis: qué nos enseñan los fighting scholars (académicos luchadores) sobre el habitus. Astrolabio, n.12, 2014. ISSN 1668-7515. Disponible en: https://revistas.psi.unc.edu.ar/index.php/astrolabio/article/view/7618. Acceso en: 3 de set. 2020.

Poniendo al habitus en su lugar: réplica del simposio. Revista Latinoamericana de Estudios sobre Cuerpos, Emociones y Sociedad, n15, p. 40-52, 2014b. ISSN: 1852-8759. Disponible en: http://www.relaces.com.ar/index.php/relaces/article/viewArticle/338 Acceso en: 3 de set. 2020

WHITE, R., RENTSCHLER, R. Toward a new understanding of the social impact of the arts". VIII International Conference on Arts \& Cultural Management, HEC, Montreal. Disponible en: http://neumann.hec.ca/aimac2005/PDF_Text/WhiteTR_RentschlerR.pdf. Acceso en: 1 de set. 2020.

WINOCUR, Rosalía. De las políticas a los barrios: programas culturales y participación popular. Buenos Aires: Ed. Miño y Dávila, 1996.

YÚDICE, G. El recurso de la cultura. Usos de la cultura en la era global. Barcelona: Gedisa, 2002. 